\title{
ENVIROMENT AND HEALTH IN INDIA
}

\section{Lalita S. Roychoudhary, N. K. Bahekar and Y. M. Maskare}

S. S. Girl"s College, Gondia, (M.S.), India.

Corresponding author Email : roy0071alita@gmail.com

\begin{abstract}
:
India is one of the most degraded environment countries in the world and it is paying health and economic price for it. Urban air pollution costs India US \$ 1.3 billion a year. Water degradation leads to health costs amounting to US \$ 5.7 million every year, nearly 60 percent of the total environment cost. Soil erosion affects 83 to 163 million hectares of land every year. Beside, land degradation leads to productivity loss equal to US $\$ 2.4$ billion or 4 to 6.4 percent of the agricultural productivity every year (UNDP 2008). All these in turn lead to an increase in the pollution levels. Also the unplanned location of industries in urban and sub-urban areas followed by traffic congestion, poor housing, poor drainage and garbage accumulation causes serious pollution problems. However, all these factors together not only lead to deteriorating environmental conditions but also have adverse effects on the health of people. The peoples in environment polluted areas are infected by pollution related diseases. Due to air pollution water pollution triggers the number of patients suffering from acute water borne diseases. The present paper is an attempt to examine population growth, increasing urbanization and its influence on the environment and health of the people.
\end{abstract}

\section{Keywords:}

Environmental pollution, GDP, Industrialization, population growth, tuberculosis, Urbanization

\section{Introduction:}

The great increase in population, together with more spectacular rise in the proportion inhabiting urban places and fast industrialization generate grave problems of environment pollution never before encountered or such a massive scale. Twentieth century men possess the technical capability and the incentive to transform large segments of the earth"s surface. So long as man lived in small, scattered settlements and no longer function without massive human intervention the problem of waste disposal solid or liquid or gaseous was not a problem of concern. Early in this century with rapid industrialization and urbanization conservationists mainly worried about the supply of raw materials 
and energy, now their primary concerns are the disposal of toxic and voluminous wastes and human health. These problems are more alarming in developing countries like our"s mainly, arising from poverty and underdevelopment. India is the world"s sixth largest and second fastest growing producer of greenhouse gases. Delhi, Mumbai and Chennai are three of the world"s ten most populated cities. Two-thirds of city dwellers lack sewerage, onethird lack potable water. India grows equivalent of another New York City every year in its urban population. By the year 2020, more than 360 million Indians will live in cities. In 15 years, more than half of India half of Indians will be urban dwellers; $1 / 3$ will be slum dwellers and squatters (downloaded from http:// www.usaid. gov/in/ programareas/ environm.htm). Inadequate water and sanitation coverage is one of the most serious environment problems (Sumeet, p 123). It has been estimated that 80 percent of the diseases in the world are associated with water usage of poor environmental hygiene (Sumeet p. xvii). Keeping these facts in mind the present paper cover diverse aspects of the pollution and its impact on human health and discuss complexity of problems emerging due to environmental pollution.

\section{Material and Method:}

For the analysis of the population data have been used to study the present scenario and as well as its nature in last decade. The statistical information was collected from the census hand book (2001\&2011 Soft Copy), offices of the statistical department and related articles.

\section{Result and Discussion:}

Demographic Characteristics of the population of India India supports 16.87 percent of the world"s population on its meager 2.4 percent world surface area of 135.79 million square $\mathrm{kms}$. The selected demographic characteristics of the population of India are presented in Table 1. At the time of independence country"s population was 342 million. The country"s population size had grown 
from 361 million in 1951 to around 846 million in 1991, 1027 million in 2001 and 1210 million in 2011. The population of India almost tripled during the period of 1951-2001. The phenomenal increase in the population during the last fifty years has led to rapid industrializations and high rate of urbanization which have, created tremendous pressure on natural resources like land, air and water. The urban population has increased three and half times, from 62.4 million in 1951 to 217.6 million in 1991 while it has increased to 288 million in 2001 and it again increased to 309 million in 2011. The percentage of urban population increased from 17.28 in 1951 to 23.33 percent in 1981, 25.71 percent in 1991, 28 percent in 2001 and which further increased to 31.39 percent in 2011. The decadal growth raters of the population are irregular, as it increased from 13.31 percent in 1951 to 24.8 percent in 1971 and afterwards it marginally declined to 24.7 percent in 1981, 23.9 percent in 1991, 21.34 percent in 2001 and 17.6 percent in 2011. The urban growth lead to an increase in the pollution levels and exposes population to serious environmental health hazards. Environmental pollution in urban areas is associated with excessive morbidity and mortality. Overcrowding and inadequate housing contribute to pollution related diseases such as respiratory diseases, acute water borne diseases tuberculosis, meningitis and various other diseases. Lack of opportunities for gainful employment in villages and the ecological stresses a leading to an ever-increasing movement of poor families to towns. Mega cities are emerging and urban slums are expanding. There have been three and half times increase in urban population over, 1951-1991. During past two decades of 1971-1991, India"s urban population has doubled from 109 million to 218 million and is estimated to reach 300 million by 2020 AD. Such rapid and unplanned expansion of cities has resulted in degradation of urban environment. It has widened the gap between demand and supply of infrastructure services such as energy, housing, transport, communication, education, water supply and sewerage and recreational activities, this depleted the precious scarce environmental resource base of the cities. The result it the 
growing trend in air water quality, generation of wasters, and the proliferation of slums and undesirable land use change, all of which contribute to urban poverty. Table 1: Selected demographic characteristics of the population of India, 1951-2011 Year Population(in millions)* Rate (\%) Decadal Growht (in million)* Urban population \%of Urban population to total population* Density (Per Sq. Kms.)* \%of population below poverty line** 1951361.113 .3162 .4 17.2811754 .8811961439 .221 .6478 .917 .9614251 .3121971548 .224 .80 109.119 .9017744 .4531981683 .324 .66159 .423 .3321058 .8641991846 .3 23.86217 .625 .7126735 .9752001102721 .34287 .628 .3932420111210 17.6369 .732382 Source: *Census of India, Provisional population Total, 2011. ** Planning Commission Estimates refers periods: 11973-74,21977$78,31983,41987-88,51993-94$ Poverty is said to be both cause and effect of environment degradation. The poor people, who rely on natural resources more than the rich, deplete natural resources faster as they have no real prospects of gaining access to other types of resources. Poorer people, who cannot meet their subsistence needs through purchase, are forced to use common property resources such as forests for food and fuel, pastures for fodder, and ponds and rivers for water. Clean drinking water facility through taps is available to only 39 percent of urban households and 22 percent of rural households in India. Urban population is also using rivers to dispose of untreated sewage and industrial effluent. The result is that health of those depends on untreated water resources are increasing at risk. In the absence of capital resources, the poor are directly dependent on natural resources. Although there has been significant drop in the poverty ratio in the country from 55 percent in 1973 to 36 percent in 1993-94, the absolute number of poor have, however, remained constant at around 320 million over the years. Acceleration in poverty alleviation is imperative to break this link between poverty and the environment. The poverty and rapid population growth are found to coexist and thus seems to reinforcing each other. It also contributes to environmental degradation through over exploitation of natural resources like land, air and 
water. The deterioration of natural resources and unsafe living conditions affects the environment and health of the poor people. Land/Soil Degradation Directs impacts of agricultural development on the environment arise from forming activities, which contribute to soil erosion, land salination and loss of nutrients. Out of the total geographical area of 328.7 million hectares, 175 million hectares are considered to be land-degraded area. Water and wind erosion is the major contributor of 141.3 million hectares to soil erosions, with other factors like water logging 8.5 million hectares, alkali soil 3.6 million hectares, acid soil 4.5 million hectares, saline soil including coastal sandy areas 5.5 million hectares adding to the situ degradation. Air Pollution Some of the most important air pollutants are suspended particulate matter (SPM), nitrogen oxides (NOx), Carbon monoxide (CO), lead, sulphur dioxide (SOa) etc. The main factors accounts to urban air quality deterioration are growing industrialization and increasing vehicular pollution, industrial emissions, automobile exhaust and the burning of fossil fuels kills thousands and live many more to suffer mainly form respiratory damage, heart and lung diseases. According to a study, 84,000 deaths were directly attributed to outdoor air pollution in Indian cities (WHO, 2006) Vehicular Pollution Urbanization in India, pressure on urban transport is like to increase substantially in this new millennium. India is expected to have 35 metro cities by 2015 and 51 by 2021 . Urban transport demand is expected to grow by 206 times by 2016 at the existing model split in larger medium sized cities. At the existing model split, the urban air quality is expected to deteriorate faster in the 21 st century, as two-wheeler population would be as high as $87.43 \%$ of the total vehicles used for passenger transportation. Water Pollution and Its Impact on Human Health According to the scientists at the National Environmental Engineering and Research Institute, a staggering $70 \%$ of the available water in India is polluted. Only five states, Maharashtra, Gujrat, Delhi, Utter Pradesh and West Bengal, generate more than $63 \%$ of the total waste water in India as they lack treatment facilities (Down to Earth, July 15, p. 19). Sewage generated from 25 
heavy polluting cities and towns account for about 75 percent of the pollution load in the river. The increasing river water pollution is the biggest threat to public health. The diseases commonly causes due to polluted water are cholera, diarrhea, hepatitis, typhoid amoebic and bacillary, dysentery, guinea worm, whereas scabies, leprosy, trachoma and conjucvitis are some of the diseases associated with water scarcity. All these could be attributed to the rapidly increasing population and lack of water resources.. It is estimated that 63 million workdays are lost every year due to water related diseases.

\section{Conclusion:}

There is a need to control population growth in the country. Wastewater treatment plants should be established in accordance with the need of time and its usage should be encouraged. The heavy penalty should be imposed on industries disposing off the wastes into the river. Moreover, the landfills are to be properly managed to prevent ground water contamination. Since slums are one of the major sources of water pollution proper measures should be taken to facilitate the slums with water and sanitation facilities. More emphasis should be laid on compulsory environmental education at the school level in order to make people aware of the environment protection. The environment protection should not be a responsibility of government alone but mass and local leaders should be encouraged to make dedicated efforts to eradicate the environmental problems.

\section{Reference:}

Census Hand book of India, (2001\&2011 Soft Copy). Dudi, R.S, (2011): Environment and Society, Neha Publishers \& Distributors, New Delhi002 .

Ghosh, B.N, (1987): Fundamental of Population Geography, Sterling publishers private Limited, New Delhi -110 016, pp.87. 
Knowles, R.,Wareing, J.(1990): „Economic and Social Geography", Rupa Company, London.

Table 1: Selected demographic characteristics of the population of India, 1951-2011

\begin{tabular}{|c|c|c|c|c|c|c|}
\hline Year & $\begin{array}{c}\text { Population(in } \\
\text { millions)* } \\
\text { Rate (\%) }\end{array}$ & $\begin{array}{c}\text { Decadal } \\
\text { Growht (in } \\
\text { million)* }\end{array}$ & $\begin{array}{c}\text { Urban } \\
\text { population }\end{array}$ & $\begin{array}{c}\text { \%of Urban } \\
\text { population to } \\
\text { total } \\
\text { population* }\end{array}$ & $\begin{array}{c}\text { Density } \\
\text { (Per Sq. } \\
\text { Kms.)* }\end{array}$ & $\begin{array}{c}\text { \%of } \\
\text { population } \\
\text { below } \\
\text { poverty } \\
\text { line** }\end{array}$ \\
\hline 1951 & 361.1 & 13.31 & 62.4 & 17.28 & 117 & $54.88^{1}$ \\
\hline 1961 & 439.2 & 21.64 & 78.9 & 17.96 & 142 & $51.31^{2}$ \\
\hline 1971 & 548.2 & 24.80 & 109.1 & 19.90 & 177 & $44.45^{3}$ \\
\hline 1981 & 683.3 & 24.66 & 159.4 & 23.33 & 210 & $58.86^{4}$ \\
\hline 1991 & 846.3 & 23.86 & 217.6 & 25.71 & 267 & $35.97^{3}$ \\
\hline 2001 & 1027 & 21.34 & 287.6 & 28.39 & 324 & \\
\hline 2011 & 1210 & 17.6 & 369.7 & 32 & 382 & \\
\hline
\end{tabular}

Source: *Census of India, Provisional population Total, 2011.

** Planning Commission Estimates refers periods: ${ }^{1} 1973-74,{ }^{2} 1977-78,{ }^{3} 1983,{ }^{4} 1987-88,{ }^{5} 1993-94$ 